\title{
Determination of solvent and ratio sample-solvent towards the production of oligo-glucosamine obtained from fermented tiger shrimp (Penaeus monodon) shell's chitin by using precipitation method
}

\author{
1,*Soedirga, L.C., ${ }^{1,2}$ Hardoko and ${ }^{1}$ Prameswari, G. \\ ${ }^{1}$ Food Technology Department, Faculty of Science and Technology, Universitas Pelita Harapan, \\ Jl.MH.Thamrin Boulevard 1100, Lippo Village, Tangerang 15811, Indonesia \\ ${ }^{2}$ Faculty of Fisheries and Marine Sciences, Universitas Brawijaya, Jl.Veteran No.1, Malang 65113,
} Indonesia

\author{
Article history: \\ Received: 26 May 2020 \\ Received in revised form: 17 \\ July 2020 \\ Accepted: 9 August 2020 \\ Available Online: 22 \\ September 2020
}

Keywords:

Acetonitrile,

Chitin,

Ethanol,

Oligo-glucosamine,

Precipitation,

Tiger shrimp

DOI:

https://doi.org/10.26656/fr.2017.4(6).255

\section{Introduction}

Chitin from the black tiger shrimp (Penaeus monodon) shell can be hydrolyzed into its monomer and oligomer. Chitin monomer consists of one chain such as $\mathrm{N}$-acetylglucosamine and D-glucosamine, while chitin oligomer such as oligo-glucosamine consists of 2-10 chains. The hydrolysis process can be done by using chitinolytic microbes that can produce chitinase enzymes, such as Providencia stuartii (Soedirga et al., 2019). Chitin hydrolysis into its monomer such Nacetylglucosamine has been widely studied. Nurrohmawati and Herdyastuti (2016) conduct a study to precipitate amorphous chitin by using ethanol and acetonitrile in the multilevel purification to produce $\mathrm{N}$ acetylglucosamine. Besides, Halim et al. (2018) carried out the purification and characterization of $\mathrm{N}$ acetylglucosamine obtained from fermented chitin by using Trichoderma virens. Methanol was used to produce $\mathrm{N}$-acetylglucosamine with the highest concentration. However, the study of oligo-glucosamine isolation has been rarely conducted. Oligo-glucosamine itself also has some functional properties such as antimicrobial, biomedical, or in the pharmaceutical field
(Jian and Yumin, 2000; Phil et al., 2018).

In this research, the isolation process of oligoglucosamine was done according to the principle of solubility or like dissolve like. This principle shows that the polar solvent will bind the polar compound and vice versa. The lesser the chain of monomer, the polar the compound (Poole and Poole, 2010). This research began with the enzymatic fermentation of black tiger shrimp (Penaeus monodon) chitin by using Providencia stuartii. Then, the fermented chitin will be isolated into oligo-glucosamine or oligomer chitin with the precipitation method by using a different type of polar organic solvents and the different ratio between sample and solvent. The precipitation method was chosen to isolate oligo-glucosamine due to its simplicity and less time-consuming. Moreover, the result obtained from the precipitation method has the highest level of purity. The objectives of this research were to determine the best polar solvent and the best ratio of sample-solvent to produced oligo-glucosamine isolate with the highest concentration. 


\section{Materials and methods}

\subsection{Materials}

The main materials used in this research were black tiger shrimp shell obtained from South Jakarta, Indonesia, and bacterial isolate Providencia stuartii obtained from previous research conducted by Hardoko et al. (2020). Providencia stuartii was isolated from decay of Penaeus monodon shells and head part. While, the supporting materials were methanol $(99.8 \%$, p.a) (Smart Lab), ethanol (99.7\%, p.a) (Smart Lab), acetone (99.5\%, p.a) (Smart Lab), acetonitrile (99.9\%, p.a) (Merck), dimethyl sulfoxide $(99.9 \%$, p.a) (Merck), N,N',N' '-Triacetylchitotriose as oligo-glucosamine standard (Dextra), Nutrient Agar (Merck), Nutrient Broth (Merck), Hydrochloric acid (1M, 37\%, p.a) (Merck), sodium hydroxide $(0.1 \mathrm{~N}, 3.5 \%$, p.a) (Merck), dipotassium phosphate $\left(\mathrm{K}_{2} \mathrm{HPO}_{4}\right)$ (Merck), potassium dihydrogen phosphate $\left(\mathrm{KH}_{2} \mathrm{PO}_{4}\right)$ (Merck), ammonium sulfate $\left.\left(\mathrm{NH}_{4}\right)_{2} \mathrm{SO}_{4}\right)$ (Merck), and magnesium sulfate heptahydrate $\left(\mathrm{MgSO}_{4 \cdot 7} \mathrm{H}_{2} \mathrm{O}\right)$ (Merck).

\subsection{Research methods}

In this experiment, two treatments were used, i.e. type of polar solvents and ratio between sample-solvents. The type of polar solvents used was ethanol, acetone, acetonitrile, ethanol: acetone $(1: 1, \mathrm{v} / \mathrm{v})$, ethanol acetonitrile $(1: 1, \mathrm{v} / \mathrm{v})$, and acetone: acetonitrile $(1: 1, \mathrm{v} / \mathrm{v})$. Meanwhile, the ratio sample between the sample and solvents used were 1:1 (v/v) and 1:2 (v/v) based on the initial volume. This experiment used 3 replications.

\subsubsection{Chitin preparation}

Chitin used in this research was obtained from the shrimp shell powder obtained from the sun drying process. The making of dried shrimp shell powder and chitin was done according to Soedirga et al. (2019). The ash content was measured according to AOAC (2005). Yield and ash content of shrimp shell powder can be calculated using formula:

$$
\begin{gathered}
\% \text { Yield: } \frac{\text { weight of dried shrimp shell powder }(\mathrm{g})}{\text { weight of shrimp shell }} \times 100 \% \\
\% \text { Ash content : } \frac{\text { weight of final sample }(\mathrm{g})}{\text { weight of initial sample }(\mathrm{g})} \times 100 \%
\end{gathered}
$$

Besides, the protein content of shrimp shell powder will be analyzed using Bradford method that refers to Pomeranz (2013). The sample absorbance will be compared to the standard curve of bovine serum albumin (BSA) to determine the protein content.

Shrimp shell powder will be demineralized and deproteinated to obtain chitin. The chitin was then analyzed according to the FTIR method (Biskup et al., 2012 with modification). In this method, the absorbance of chitin was measured by using an infra-red spectrophotometer at a wavelength $400-4000 \mathrm{~cm}-1$ in the room temperature. The absorbance of the amide group (A1655) will be compared to the absorbance of the primary group of amines (A3450) to determine the degree of deacetylation, as shown in this formula:

$$
\% \text { Degree deacetylation (DD): } 1-\frac{\mathrm{A} 1655}{\mathrm{~A} 3450} \times \frac{1}{1.33} \times 100 \%
$$

Moreover, the yield, ash content and protein content of the chitin were measured. The calculation of ash and protein content was done using the same method and formula for ash and protein content of shrimp shell powder, while the yield of chitin was calculated using this formula:

$$
\% \text { Yield: } \frac{\text { weight of chitin powder }}{\text { weight of shrimp shell powder }} \times 100 \%
$$

\subsubsection{Chitin fermentation}

Chitin was then used as a material for the fermentation process along with other materials. The fermentation medium composition mentioned in Table 1. The working culture was prepared by 18 hours incubation of Providencia stuartii, as the chitinolytic microbes in this experiment. About $2 \mathrm{~mL}$ of working culture were inoculated into the prepared fermentation medium under aseptic condition then the fermentation process was continued in the incubator at $40^{\circ} \mathrm{C}$ under constant stirring at speed $200 \mathrm{rpm}$ (Ghorbel-Bellaaj et al., 2012; Halim et al., 2018).

\begin{tabular}{lc}
\multicolumn{2}{c}{ Table 1. Fermentation medium composition } \\
\hline Material & Amount \\
\hline Distilled water & $400 \mathrm{~mL}$ \\
Chitin powder & $40 \mathrm{~g}$ \\
Nutrient Broth & $3.2 \mathrm{~g}$ \\
$\mathrm{KH}_{2} \mathrm{PO}_{4}$ & $0.12 \mathrm{~g}$ \\
$\mathrm{~K}_{2} \mathrm{HPO}_{4}$ & $0.28 \mathrm{~g}$ \\
$\mathrm{MgSO}_{4} \cdot 7 \mathrm{H}_{2} \mathrm{O}$ & $0.04 \mathrm{~g}$ \\
$\left(\mathrm{NH}_{4}\right)_{2} \mathrm{SO}_{-4}$ & $2.8 \mathrm{~g}$ \\
\hline
\end{tabular}

After 4 days, the result was subjected to heat treatment in the water bath at $70^{\circ} \mathrm{C}$ for 45 mins to kill the bacteria. The result was then filtered using Buchner to separate the supernatant and the pellet. The supernatant was then centrifuged at $5000 \mathrm{rpm}$ for $10 \mathrm{mins}$ (Herdyastuti et al., 2009; Saskiawan and Handayani, 2011). The pellet was discarded, while the supernatant was collected for the further step.

\subsubsection{Oligo-glucosamine isolation}

Isolation method of oligo-glucosamine was done according to Jovanovic-Malinovska et al. (2015); Katano et al. (2017); Babbar et al. (2016); Halim et al. (2018) with modification. The supernatant obtained from the previous step was then added with methanol $(1: 1, \mathrm{v} / \mathrm{v})$ 
and let stand for $1 \mathrm{hr}$ to precipitate the $\mathrm{N}$ acetylglucosamine component, which is a monomer from chitin fermentation. The precipitate was then subjected to the centrifugation at $5000 \mathrm{rpm}$ for 15 mins.

The resulted supernatant was then precipitated again with the treatment solvents for $1 \mathrm{hr}$ at room temperature to isolate the oligo-glucosamine. The ratio between sample and solvent was adjusted according to the treatment. Solvent volume was added based on the initial volume of supernatant before the precipitation using methanol.

The supernatant produced from the methanol precipitation was then precipitated with solvents for $1 \mathrm{hr}$ at room temperature. The selection of polar solvents, as well as the ratio between sample and solvents, was determined according to the treatment. The volume of polar solvents was determined based on an initial volume of supernatant before the methanol precipitation.

The mixture was then centrifuged at a speed of 5000 rpm for 15 mins. The pellet obtained was oligoglucosamine. Furthermore, the yield of oligoglucosamine was calculated with two different approaches (based on the volume obtained after fermentation and based on the weight of chitin used for fermentation) as shown in these formulae:

$$
\begin{aligned}
& \% \text { Yield (w/v): } \frac{\text { weight of oligoglucosamine }}{\text { volume of mixture after fermentation }} \times 100 \% \\
& \% \text { Yield }(w / w): \frac{\text { weight of oligoglucosamine }}{\text { weight of chitin used for fermentation }} \times 100 \%
\end{aligned}
$$

\subsubsection{Determination of oligo-glucosamine concentration}

The concentration of oligo-glucosamine was analyzed according to Behera et al. (2012) and Saskiawan and Handayani (2011) with modification. The $\mathrm{N}, \mathrm{N}$, N', - Triacetylchitotriose (NTC) was used as a standard because of the molecular weight of NTC close to the molecular weight of oligo-glucosamine fragment identified from the previous research $(611.4085 \mathrm{Da})$. The analysis has consisted of four steps, i.e. determination of the maximum wavelength of the standard, the making of the standard curve, the absorbance measurement of oligo -glucosamine isolate, and the calculation of oligoglucosamine concentration itself.

The standard curve was made based on the absorbance measurement of NTC standard within a concentration of 100-1000 ppm at wavelength 200-800 $\mathrm{nm}$. The blank used is DMSO (Behera et al., 2012). Meanwhile, the oligo-glucosamine isolate will be dissolved in distilled water and measured at the same wavelength as those used to measure the standard curve.
The oligo-glucosamine concentration is expressed as $\mathrm{mg} / \mathrm{g}$ Triacetylchitotriose equivalent (ppm NTCE). The equivalent can be defined as equal or directly proportional. Therefore, the oligo-glucosamine concentration is equal to the NTC concentration. This approach is in a similar way to express phenolic concentrations as gallic acid equivalents.

\subsubsection{Data analysis}

The data obtained in this experiment were analyzed using SPSS version 16.0 software, which includes analysis of variance (ANOVA) and Duncan post hoc test.

\section{Results and discussion}

\subsection{Characteristics of shrimp shell powder and chitin}

At the initial stage of this research, several analyses were performed to determine the characteristics of shrimp shell powder and chitin that used for oligoglucosamine isolation. The percentage of yield, ash content, and protein content of chitin were lowered compared to shrimp shell powder. The result can be observed in Table 2.

Table 2. Result of analyses for shrimp shell powder and chitin

\begin{tabular}{lcc}
\hline Analyses & Shrimp shell & Chitin (\%) \\
\hline Yield & $31.52 \pm 0.09$ & $20.36 \pm 0.18$ \\
Ash content & $38.52 \pm 0.28$ & $0.23 \pm 0.02$ \\
Protein content & $17.64 \pm 0.81$ & $0.80 \pm 0.03$ \\
Degree of deacetylation & - & 32.85 \\
\hline
\end{tabular}

The initial protein content in the shrimp shell powder is $17.64 \%$. The addition of hydrochloric acid and base solution during deproteination could lower the protein content to $0.8 \%$ compared to the initial protein content, therefore, it has shown the completion of deproteination process. Besides, some of the minerals on the shrimp shell powder such as calcium, magnesium, phosphor, and iron; have been lost during demineralization, therefore, the ash content of chitin $(0.23 \%)$ lowered compared to the ash content of shrimp shell powder $(28.52 \%)$. The lesser content of ash and protein in chitin lead to the weight reduction of chitin, hence, the value of chitin yield is also lowered.

According to Beil et al. (2012), chitin has a degree of deacetylation below $60 \%$, whereas if the value above $60 \%$ is chitosan. Chitosan is a chitin-derived polysaccharide compound that has lost its acetyl group (Hossain and Iqbal, 2014). Table 2 shows the degree of deacetylation of chitin in this research is $32.85 \%$. It shows that the demineralization and deproteination processes undoubtedly is chitin, not chitosan. 
3.2 Determination of solvents and ratio sample-solvents for production of oligo-glucosamine isolate

The yield for each fraction of oligo-glucosamine isolate can be observed in Table 3. Overall, the ratio 1:2 $(\mathrm{v} / \mathrm{v})$ for sample-solvents for each fraction results higher yield than ratio $1: 1(\mathrm{v} / \mathrm{v})$. At a ratio $1: 2$, the total volume of solvent used is more, therefore, the possibility of contact between sample and solvent is also higher. The higher contact between sample and solvents cause the higher possibility of oligo-glucosamine precipitation and results in a higher yield (Azwanida, 2015).

Table 3. Yield oligo-glucosamine with ratio 1:1 of samplesolvent $(\mathrm{v} / \mathrm{v})$

\begin{tabular}{lcc}
\hline $\begin{array}{c}\text { Type of polar } \\
\text { solvents }\end{array}$ & $\begin{array}{c}\text { Yield (v/v,\%, based on } \\
\text { Yhe volume obtained } \\
\text { after fermentation) }\end{array}$ & $\begin{array}{c}\mathrm{w} / \mathrm{v}, \% \text {, based on } \\
\text { the weight of chitin } \\
\text { used for fermentation) }\end{array}$ \\
\hline $\begin{array}{l}\text { Ethanol } \\
\text { Acetone }\end{array}$ & $0.11 \pm 0.01$ & $0.08 \pm 0.01$ \\
Acetonitrile & $0.19 \pm 0.02$ & $0.15 \pm 0.02$ \\
$\begin{array}{l}\text { Ethanol: } \\
\text { Acetone }\end{array}$ & $0.09 \pm 0.01$ & $0.07 \pm 0.01$ \\
$\begin{array}{l}\text { Ethanol: } \\
\text { Acetonitrile }\end{array}$ & $0.16 \pm 0.01$ & $0.12 \pm 0.01$ \\
Acetone: & $0.12 \pm 0.01$ & $0.09 \pm 0.01$ \\
\end{tabular}

Results from ANOVA showed that type of polar solvents and ratio sample-solvents gave a significant effect on the oligo-glucosamine concentration $(p<0.05)$. Besides, there was also a significant effect on the interaction between type of polar solvents and ratio sample-solvents on the oligo-glucosamine concentration (Figure 1). According to Figure 1, the concentration of oligo-glucosamine obtained from the precipitation with a combination of ethanol and acetonitrile within ratio $1: 1$ $(\mathrm{v} / \mathrm{v})$ significantly higher compared to another fraction $(p<0.05)$, which reached $1059.90 \pm 23.51 \mathrm{mg} / \mathrm{g}$ NTCE.

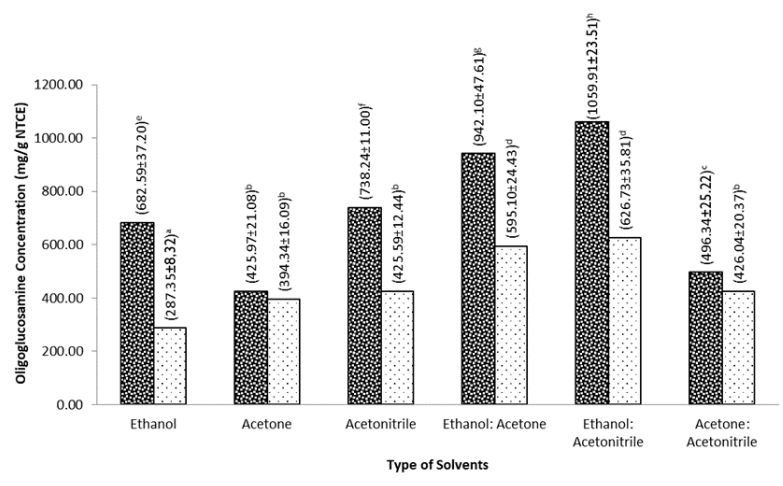

Figure 1. Oligo-glucosamine concentration obtained from precipitation with different type of polar solvents and ratio sample-solvents. Bars with different superscript letters indicate significant difference $(\mathrm{p}<0.05)$

Acetonitrile and ethanol have a higher polarity index (5.8 and 5.2, respectively) compared to acetone (5.1) (Wyatt, 2014). N-acetylglucosamine consists of 1 chain, while oligo-glucosamine consists of 2-10 chains. Although, oligo-glucosamine less polar compared to Nacetylglucosamine, but some of the oligo-glucosamine with short chain oligomer could bind with a polar solvent, especially polar solvent with a higher polarity index. Consequently, the oligo-glucosamine will be precipitated by both solvents and resulted in the highest concentration (Poole and Poole, 2010; Katano et al., 2017)

Another explanation to support combination ethanol and acetonitrile as the selected solvent was related to the characteristic of each solvent. According to Katano et al. (2017), acetonitrile has a higher value of dielectric constant and able to precipitate $\mathrm{N}$-acetylglucosamine oligomer with a short chain $(n \leq 3)$. The NTC standard used in this research consists of 3 chains of oligomer, thus the absorbance of oligo-glucosamine measured was expected the oligo-glucosamine with three chains of monomers, which can precipitate by the acetonitrile. The concentration of oligo-glucosamine obtained from the isolation using acetonitrile significantly lowered $(738.24 \pm 11.00 \mathrm{mg} / \mathrm{g}$ NTCE) compared to selected solvents at the same ratio, thus it also shown that acetonitrile has an ability to precipitate the oligoglucosamine.

Due to the presence of $-\mathrm{NH},-\mathrm{OH}$, and $-\mathrm{C}=\mathrm{O}$ groups, oligo-glucosamine able to dissolve in water and support the formation of hydrogen bond as well as an ionic bond. However, the addition of ethanol could disrupt the hydrogen and ionic bond, which lead to weak binding within oligo-glucosamine thus resulted in the precipitation of oligo-glucosamine (Reichardt and Welton, 2011; Nurrohmawati and Herdyastuti, 2016). This theory also supports the result obtained. The concentration of oligo-glucosamine obtained from the isolation using ethanol significantly different (682.59 $\pm 37.02 \mathrm{mg} / \mathrm{g}$ NTCE). Although significantly lowered compared to selected solvents and acetonitrile at the same ratio, but it also showed the ability of ethanol to precipitate oligo-glucosamine.

A higher concentration of oligo-glucosamine demonstrates a higher purity of isolate. However, the purity of isolate oligo-glucosamine inversely correlated with the yield. According to Table 3, the selected solvents produced oligo-glucosamine with a lower yield which is $0.12 \%$ (based on the volume obtained after fermentation) or $0.09 \%$ (based on the weight of chitin used for fermentation). On the contrary, acetone with ratio 1:2 (v/v) exhibit the highest yield of oligoglucosamine isolate within the value of $0.95 \%$ (based on the volume obtained after fermentation) or $0.48 \%$ (based on the weight of chitin used for fermentation). This 
solvent produces oligo-glucosamine with the concentration of $394.34 \pm 16.09 \mathrm{mg} / \mathrm{g}$ NTCE which was quite low compared to the concentration of selected solvents.

This result indicated that acetone was also able to precipitate oligo-glucosamine with various chain and several other impurities. Kazami et al. (2015) stated that acetone have an ability to precipitate chitin oligomer with 4-6 chains and 7-13 chains. Polarity index of acetone also lower rather than ethanol and acetonitrile, so that, it is unable to precipitate the lesser chain of oligo -glucosamine isolate, such as oligo-glucosamine with 3chains which obtained in this study.

\section{Conclusion}

The combination of ethanol and acetonitrile $(1: 1, \mathrm{v} /$ v) and ratio sample-solvent $1: 1(\mathrm{v} / \mathrm{v})$ produced oligoglucosamine with the highest concentration $(1059,90 \pm 23,51 \mathrm{mg} / \mathrm{g}$ NTCE). Moreover, the yield obtained from this selected solvent is $0.12 \%$ (based on the volume obtained after fermentation) or $0.09 \%$ (based on the weight of chitin used for fermentation).

\section{Conflict of Interest}

The authors declare no conflict of interest.

\section{Acknowledgments}

The authors would like to thank CRCD (Centre for Research and Community Development) Universitas Pelita Harapan for research project funding 2019.

\section{References}

AOAC. (2005). Official Methods of Analysis of The Association of Official Analytical Chemist. $18^{\text {th }}$ ed. Washington: Benjamin Franklin Station.

Azwanida, N.N. (2015). A review on the extraction methods use in medicinal plants, principle, strength, and limitation. Med Aromatic Plants, 4(3), 1-6. https://doi.org.10.4172/2167-0412.1000196.

Babbar, N., Dejonghe, W., Gatti, M., Sforza, S. and Elst, K. (2016). Pectic oligosaccharides from agricultural by-products: production, characterization, and health benefits. Critical reviews in biotechnology, 36(4), 594-606. doi.org/10.3109/07388551.2014.996732.

Behera, S., Ghanty, S., Ahmad, F., Santra, S. and Benerjee, S. (2012). UV visible spectrophotometric method development and validation of assay of paracetamol tablet formulation. Journal of Analytical and Bioanalytical Techniques 3(6),1-6. https:// doi.org/10.4172/2155-9872.1000151.

Beil, S., Schamberger, A., Naumann, W., Machill, S. and van Pée, K.H. (2012). Determination of the degree of n-acetylation (DA) of chitin and chitosan in the presence of water by first derivative ATR FTIR spectroscopy. Carbohydrate Polymers, 87(1), 117122. https://doi.org/ 10.1016/j.carbpol.2011.07.025.

Biskup, R.C., Jarosinska, D., Rokita, B., Ulanski, P. and Rosiak, J.M. (2012). Determination of degree of deacetylation of chitosan comparison of methods. Progress on Chemistry and Application of Chitin and its Derivatives, 17, 5-20.

Ghorbel-Bellaaj, O., Younes, I., Maâlej, H., Hajji, S. and Nasri, M. (2012). Chitin extraction from shrimp shell waste using Bacillus bacteria. International Journal of Biological Macromolecules, 51(5), 1196-1201. https://doi.org/10.1016/j.ijbiomac.2012.08.034.

Halim, Y., Hardoko, Handayani, R. and Lucida, V. (2018). Optimum conditions for n-acetyl glucosamine production from tiger shrimp (Penaeus monodon) shell by Serratia marcescens. Asian Journal of Pharmaceutical and Clinical Research, 11(12), 488-493. https://doi.org/10.22159/ ajpcr.2018.v11i12.28956.

Hardoko, Josephine, C., Handayani, R. and Halim, Y. (2020). Isolation, identification, and chitinolytic index of bacteria from rotten tiger shrimp (Penaeus monodon) shells. AACL Bioflux, 13(1), 360-371.

Herdyastuti, N., Raharjo, T.J., Mudasir and Sabirin. (2009). Chitinase and chitinolytic microorganism: isolation, characterization, and potential. Indonesian Journal of Chemistry, 9(1), 37-47. https:// doi.org/10.22146/ijc. 21580

Hossain, M.S. and Iqbal, A. (2014). Production and characterization of chitosan from shrimp waste. Journal of the Bangladesh Agricultural University, 12(1), 153-160. http:// dx.doi.org/10.3329/jbau.v12i1.21405.

Jian, S. and Yumin, Y. (2000). Hygroscopicity, moisture retention and anti-microbial activity of oligoglucosamine. Chinese Journal of Marine Drugs, 19 (4), 25-27.

Jovanovic-Malinovska, R., Kuzmanova, S. and Winkelhausen, E. (2015). Application of ultrasound for enhanced extraction of prebiotic oligosaccharides from selected fruits and vegetables. Ultrasonics Sonochemistry, 22, 446-453. https://doi.org/10.1016/ j.ultsonch.2014.07.016

Katano, H., Noba, S., Sato, K. and Kimoto, H. (2017). Solubility-based separation and purification of longchain chitin oligosaccharides with organic-water mixed solvent. Analytical Sciences, 33(5), 639-642. 
https://doi.org/10.2116/analsci.33.639

Kazami, N., Sakaguchi, M., Mitzutani, D., Masuda, T., Wakita, S., Oyama, F., Kawakita, M. and Sugahara, Y. (2015). A simple procedure for preparing chitin oligomers through acetone precipitation after hydrolysis in concentrated hydrochloric acid. Elsevier Carbohydrate Polymers, 132, 304-310. https://doi.org/10.1016/j.carbpol.2015.05.082

Nurrohmawati, F.D. and Herdyastuti, N. (2016). Variation of ethanol-acetonitrile in the purification of $\mathrm{N}$-acetylglucosamine resulted from enzymatic degradation of amorphous chitin. UNESA Journal of Chemistry, 5(3), 7-12.

Phil, L., Naveed, M., Mohammad, I.S., Bo, L. and Bin, D. (2018). Chito-oligosaccharide: an evaluation of physicochemical and biological properties with the proposition for determination of thermal degradation products. Biomedicine and Pharmacotherapy, 102, 438-451. https://doi.org/10.1016/ j.biopha.2018.03.108.

Pomeranz, Y. (2013). Food Analysis: Theory and Practice. $3^{\text {rd }}$ ed. New York: Springer Science and Business Media.

Poole, C.F. and Poole, S.K. (2010). Extraction of organic compounds with room temperature ionic liquids. Journal of Chromatography A, 1217(16), 2268-2286. https://doi.org/10.1016/ j.chroma.2009.09.011.

Reichardt, C. and Welton, T. (2011). Solvents and Solvent Effects in Organic Chemistry. New York: John Wiley and Sons. https:// doi.org/10.1002/9783527632220

Saskiawan, I. and Handayani, R. (2011). Production of $n$ -acetyl-d-glucosamine by submerged fermentation from chitin. Berita Biologi, 10(6), 721-728.

Soedirga, L.C., Hardoko, H. and Widianto, N.V. (2019). Production of n-acetylglucosamine from semi purified chitinase of Mucor circinelloides that immobilized by using agar. Jurnal Perikanan Universitas Gadjah Mada, 21(2), 99-104. https:// doi.org/10.22146/jfs.45886.

Wyatt, V.T. (2014). The effects of solvent polarity and $\mathrm{pKa}$ on the absorption of solvents into poly (glutaric acid-glycerol) films. Journal of Applied Polymer Science, 131(13), 1-7. https://doi.org/10.1002/ app.40434. 